\author{
William David Brice ${ }^{1}$ \\ California State University Dominguez Hills, USA
}

\author{
Edward Chu ${ }^{2}$
}

California State University Dominguez Hills, USA

Wayne Jones ${ }^{3}$

Hamdan Bin Mohammed University Academic City, Dubai, UAE

\title{
Culture-Laden Imports: International Market Entry and Cultural Taboos
}

\begin{abstract}
This empirical study investigates American market responses to a Spanish product that is strongly culture-laden and may violate cultural taboos. Surveys were conducted in two contrasting US universities in Arkansas and California. Contrasting student majors were also chosen: Art and Business. The product is a life-sized baby doll, designed to be breast-fed rather than bottle-fed, which highlights the benefits and normality of breastfeeding babies. Although this product is popular in its original European market, US media accounts suggested strongly negative morality-based American reactions. This study found a strong overall non-acceptance of this product in all groups, but with significant differences between groups. Results quantify the market reaction and illuminate its cultural basis by comparing responses between two culturally different regions, two contrasting college majors, different genders, and different ethnicities. In doing so, this study helps to break new ground in the international marketing of culture-laden products.
\end{abstract}

Keywords: international marketing, market acceptance, consumer ethnocentrism, cultural taboos

JEL: F29, M16, M31, Z10, Z13 


\section{Introduction}

This is a study of US market acceptance and non-acceptance of a Spanish doll import, called Bebe Gloton in Spain and Breast Milk Baby in the US, which is produced and distributed by Berjuan, S.L. of Alicante, Spain. Berjuan Toys sold over two million Bebe Gloton dolls in Europe [Chicago Tribune, 2011] and after a testing period starting in 2009 introduced the doll as Breast Milk Baby in male, female, and three different ethnic versions at the end of 2011. The doll has been the subject of some commentary and controversy in the US media. Commentator Bill O'Reilly denounced the doll on his Fox News show and numerous other stories in the media expressed aversion to the product [CBS News, 2012]. This US negative reaction, in the face of strong acceptance by Europeans, indicates a cultural taboo response in the US [Tews, 2014].

It might be commonly assumed that products such as toys and dolls that are used worldwide would not elicit strong taboo-related reactions; and most baby-doll-related negative reactions have centered on ethnicity issues. This may be the first baby-doll product to elicit a reaction related to sexuality issues. Importing a product into a culturally different market may easily violate cultural taboos, which are not generally talked or written about. The importing firm may therefore be unaware of them until after the transgression has already been committed. This study attempts to quantify the cultural reaction, if any, to this product by comparing responses in two culturally different regions of the US. Gender differences will be analyzed, as will differences between two contrasting college majors: Art and Business. Ethnicity will also be examined for differences in responses. Thelen [2003] found that although antecedents of consumer ethnocentrism may be significant for a nation as a whole, they are actually significant in some but not all sub-cultures. This implies that there may be significant differences in product acceptance or non-acceptance between the different regions and groups surveyed here. Charting these differences, if any, would be of importance to planning the marketing of culture-laden products.

\section{Cultural Taboos and Product Acceptance}

The international spread of US products and the ideas and attitudes embodied in US movies have supplanted traditional patterns in some countries to patterns more like those in the US. In some countries, this spread has engendered a degree of anti-American feelings. Cultural closeness to the US is associated with a greater degree of Americanization and the basic process underlying the spread of other cultures should be similar [Craig, 2009]. Activities by foreign firms will gradually result in the introduction of foreign products and ideas that may eventually become fully part of the home culture. 
Culture is the collective programming of the mind that differentiates groups of people [Hofstede, 2001]. Americanization is accepted in some countries as a manifestation of globalization and resisted in others as an attack on traditional values [Craig, 2009]. Products contribute to culture because they contain cultural meaning [McCracken, 1986]. Interpretation of products is linked to the values and beliefs of a culture. Culture is manifested in the values and norms governing objects used in everyday life and, in marketing, attention is focused on the impact of culture on individual purchasing behavior. Product ownership may define membership in a lifestyle as well as a cultural group's values, attitudes and beliefs. Wearing a headscarf may denote a value of modesty in addition to a belief in Islam. Cultural norms not only shape attitudes, lifestyles and products that characterize a particular culture. They also block the acceptance of contrary attitudes, lifestyles and products that characterize other cultures. [Craig, 2009].

Taboo advertising involves topics that have a culturally forbidden status. It causes offence by violating cultural norms [Sabri, 2012a, 2012b]. Some products are more objectionable than others but Beard [2008] states that offensive themes will shock more than the advertised products. Studies of taboo products have shown that advertising them can not only be controversial. They can also be completely unacceptable [Fahy et al., 1995; Waller, 1999] However, advertisers increasingly use cultural taboos to attract attention and promote brand recognition [Pope, Voges, Brown, 2004].

Studies show that there is an optimum degree of taboo-arousal in advertising that can attract maximum attention, and that humor mitigates the negative effects of the taboo while increasing attention and recall [Cline, Kellaris, 2007; Madden, Weinberger, 1982]. There is a limit to the positive effect of using a taboo tactic, above which it becomes counterproductive. Advertisers must find the optimum level of taboo to receive the strongest attention and recall [Sabri, 2012b].

Additionally, different markets will respond differently to the same product addressing the same taboo. P\&G's line of feminine sanitary products are advertised in the US with humorous and cheeky slogans such as "Outsmart Mother Nature" or "Have a Happy Period", but in much more conservative Singapore, where this might shock, the approach is to softly encourage young women to talk openly to each other on its social-networking web site while also providing health tips and debunking myths surrounding the subject [Cheng, 2009]. Parry et al. [2013] found that public reactions to shock advertising differed according to whether it was provided by not-for-profit or for-profit organizations. They also noted that reactions differed by the religion and gender of the audience. 


\section{Hypotheses}

There is a multitude of anecdotal and statistical evidence that Arkansas culture, being part of the American bible belt and a center of religious fundamentalism in the US, is much more conservative than California culture [Bolton, Ledbetter, 1983; Roof, 2007]. The initial assumption is that this doll product will be accepted more by the less conservative California survey respondents.

H1: Arkansas respondents will show significantly greater rejection of the Bebe Gloton doll than California respondents.

Similarly, it is commonly assumed, with some statistical support, that Art students are more socially progressive than average and that Business students are more socially conservative than average [Douglas, Lamber, 1990; Van de Werforst, Kraaykamp, 2001]. Therefore, Business majors will show significantly greater rejection of the Bebe Gloton doll than do Art majors.

H2: Business majors will show significantly greater rejection of the Bebe Gloton doll than Art majors.

It is thought that women will respond more favorably to products that promote social aspects unique to their gender and progressive causes in general [Emmenegger, Manow, 2014]. In masculine cultures such as the U.S. there is a large degree of value differentiation between males and females [de Mooij, Hofstede, 2002]. Therefore, it is predicted that male respondents will show significantly greater rejection of the Bebe Gloton doll than do female respondents.

H3: Male respondents will show significantly greater rejection of the Bebe Gloton doll than female respondents.

There is no anecdotal or statistical evidence to assume that some ethnic groups will reject the Bebe Gloton doll more than others.

H4: No ethnic group will show a significantly greater rejection of the Bebe Gloton doll than other ethnic groups.

\section{Methods}

A survey instrument was administered to a total of 242 respondents on two college campuses, the University of Arkansas at Little Rock (UALR) and California State University Dominguez Hills (CSUDH). Data collection was conducted on an person-to-person 
basis, both randomly to Business and Art majors at the entrances to their respective departments and in-class to senior-class students in the same departments. Thus, there was not a response-rate issue. Excluding responses with incomplete data, a total of 144 Business students and 89 Art students were surveyed: 45 Business at UALR and 99 at CSUDH; 41 Art at UALR and 48 at CSUDH. Respondents were divided into 91 Male and 142 Female: 30 Male at UALR and 61 at CSUDH; 56 Female at UALR and 86 at CSUDH. 77 respondents were Hispanic, 71 European-American, 41 African-American, 14 Asian American, 21 Non-American, 5 other, and 4 were unidentified.

The survey instrument showed a photo of the Bebe Gloton doll product in its original packaging, and detailed the product's attributes and intended method of use. This was followed by demographic questions and a section on the respondent's reactions to the product (see survey in Appendix).

The instrument asked if there was anything "immoral" about the product if it was intended for a 5-year-old girl; if the respondent would allow their presumed 5-year-old girl to "play" with the product; and finally if they would "buy" the doll. The variable Play was chosen to be the measured dependent variable because it was the response with the least restrictive interpretation.

Due to the fact that the collected data were nominal, cross tabulation studies were conducted to test for independence between factors. Before studies were performed, cases with incomplete information were removed. Consequently, study results were based on the number of cases indicated in Tables 1 and 2.

\section{TABLE 1. Respondent demographics}

\begin{tabular}{|l|c|c|c|c|c|c|c|c|c|}
\cline { 2 - 10 } \multicolumn{1}{c|}{} & Total & Male & Female & Art & Art M & Art F & Business & Bus M & Bus F \\
\hline UALR & 86 & 30 & 56 & 41 & 13 & 28 & 45 & 17 & 28 \\
\hline CSUDH & 147 & 61 & 86 & 48 & 16 & 32 & 99 & 45 & 54 \\
\hline Total & 233 & 91 & 142 & 89 & 29 & 60 & 144 & 62 & 82 \\
\hline
\end{tabular}

Source: own elaboration.

\section{TABLE 2. Respondent ethnicity}

\begin{tabular}{|l|c|}
\hline Hispanic-American & 77 \\
\hline European-American & 71 \\
\hline African-American & 41 \\
\hline Asian-American & 14 \\
\hline Non-American & 21 \\
\hline Other American & 5 \\
\hline Total & 229 \\
\hline
\end{tabular}

Source: own elaboration. 


\section{Results}

The cross tabulation results (see Table 3 ) show significant differences on several variables with the choice to allow a child to play with the Bebe Gloton doll. School, Major and Ethnicity all varied significantly, with School having the greatest significance. The differences in School validates the assumption that Arkansas and California have different cultures; the differences between Majors show the importance of respondent self-selection into career groupings, and Ethnicity differences again show the importance of cultural attitudes. Overall results for Gender (all gender combined from both locations) did not show statistically significant results.

TABLE 3. Cross tabulation results (Pearson Chi-Square)

\begin{tabular}{|l|c|c|c|c|}
\hline & No of cases & Value & df & Asymp. Sig. (2-tailed) \\
\hline School with Play & 233 & 7.245 & 1 & $0.007^{* *}$ \\
\hline Major with Play & 233 & 4.552 & 1 & $0.033^{*}$ \\
\hline Gender with Play & 233 & 0.933 & 1 & 0.334 \\
\hline Ethnicity with Play & 229 & 15.132 & 6 & $0.019^{*}$ \\
\hline
\end{tabular}

Note: ${ }^{*}$, and ${ }^{* *}$ denote statistical significance at $5 \%$, and $1 \%$ levels (2-tailed), respectively.

Source: own elaboration.

$\mathrm{H} 1$ asserted that Arkansas respondents would show significantly greater rejection of the Bebe Gloton doll than would California respondents. Only 70 percent of Arkansas respondents would not allow their child to play with the doll compared with 83 percent of California respondents who rejected the doll for their children (see Table 4). It was found that the variable School did significantly differ with regard to the variable Play, with a Pearson Chi-Square of 0.007. Although the difference was significant, contrary to expectations, Arkansas accepted the doll more than California, and thus $\mathrm{H} 1$ is not supported.

$\mathrm{H} 2$ asserted that Business majors would show significantly greater rejection of the Bebe Gloton doll than would Art majors. 84 percent of Business majors would not allow children to play with the product compared to 69 percent of Art majors. The two groups were very close in terming the doll immoral at 60 percent for Business and 58 percent for Art (see Table 4 below). It was found that the variable Major did significantly differ with regard to the variable Play, with a Pearson Chi-Square of 0.033; thus H2 is supported.

$\mathrm{H} 3$ asserted that Male respondents would show significantly greater rejection of the Bebe Gloton doll than would female respondents. Results showed that 80 percent of Females would not allow children to play compared to 75 percent of Males. Additionally 64 percent of Females considered the product immoral compared to only 52 percent of 
Males (see Table 4 below). The survey results showed Females rejecting the doll more than males, contrary to expectations, and it was found that the variable Gender did not significantly differ with regard to the variable Play, with a Pearson Chi-Square of 0.334; thus $\mathrm{H} 3$ is not supported as far as all Males vs. all Females.

TABLE 4. Tabulated results by gender and major

\begin{tabular}{|c|c|c|c|c|c|c|c|c|c|c|}
\hline & & Total & Male & Female & Art & Business & $\begin{array}{l}\text { Male } \\
\text { Art }\end{array}$ & $\begin{array}{c}\text { Female } \\
\text { Art }\end{array}$ & $\begin{array}{c}\text { Male } \\
\text { Business }\end{array}$ & $\begin{array}{c}\text { Female } \\
\text { Business }\end{array}$ \\
\hline UALR Results & $\mathrm{N}$ & 89 & 31 & 58 & 43 & 46 & 14 & 29 & 17 & 29 \\
\hline \multirow[t]{2}{*}{ Immoral? } & Yes & $53 \%$ & $39 \%$ & $60 \%$ & $58 \%$ & $48 \%$ & $19 \%$ & $66 \%$ & $35 \%$ & $55 \%$ \\
\hline & No & $37 \%$ & $48 \%$ & $31 \%$ & $35 \%$ & $39 \%$ & $77 \%$ & $28 \%$ & $47 \%$ & $34 \%$ \\
\hline \multirow[t]{2}{*}{ Allow to Play? } & Yes & $27 \%$ & $35 \%$ & $22 \%$ & $35 \%$ & $20 \%$ & $43 \%$ & $31 \%$ & $29 \%$ & $14 \%$ \\
\hline & No & $70 \%$ & $61 \%$ & $74 \%$ & $60 \%$ & $78 \%$ & $50 \%$ & $66 \%$ & $71 \%$ & $83 \%$ \\
\hline \multirow[t]{2}{*}{ Would Buy? } & Yes & $15 \%$ & $23 \%$ & $10 \%$ & $19 \%$ & $11 \%$ & $21 \%$ & $17 \%$ & $24 \%$ & $3 \%$ \\
\hline & No & $83 \%$ & $74 \%$ & $88 \%$ & $77 \%$ & $89 \%$ & $71 \%$ & $79 \%$ & $76 \%$ & $97 \%$ \\
\hline CSUDH Results & $\mathrm{N}$ & 153 & 64 & 89 & 53 & 100 & 18 & 35 & 46 & 54 \\
\hline \multirow[t]{2}{*}{ Immoral? } & Yes & $63 \%$ & $58 \%$ & $66 \%$ & $58 \%$ & $65 \%$ & $50 \%$ & $63 \%$ & $61 \%$ & $69 \%$ \\
\hline & No & $26 \%$ & $28 \%$ & $25 \%$ & $28 \%$ & $25 \%$ & $28 \%$ & $29 \%$ & $28 \%$ & $22 \%$ \\
\hline \multirow[t]{2}{*}{ Allow to Play? } & Yes & $13 \%$ & $14 \%$ & $12 \%$ & $15 \%$ & $12 \%$ & $17 \%$ & $14 \%$ & $13 \%$ & $11 \%$ \\
\hline & No & $83 \%$ & $81 \%$ & $84 \%$ & $75 \%$ & $87 \%$ & $72 \%$ & $77 \%$ & $85 \%$ & $89 \%$ \\
\hline \multirow[t]{2}{*}{ Would Buy? } & Yes & $7 \%$ & $6 \%$ & $7 \%$ & $8 \%$ & $6 \%$ & $6 \%$ & $9 \%$ & $7 \%$ & $6 \%$ \\
\hline & No & $91 \%$ & $91 \%$ & $91 \%$ & $89 \%$ & $92 \%$ & $94 \%$ & $86 \%$ & $89 \%$ & $94 \%$ \\
\hline Combined Results & $\mathrm{N}$ & 242 & 95 & 147 & 96 & 146 & 32 & 64 & 63 & 83 \\
\hline \multirow[t]{2}{*}{ Immoral? } & Yes & $59 \%$ & $52 \%$ & $64 \%$ & $58 \%$ & $60 \%$ & $47 \%$ & $64 \%$ & $54 \%$ & $64 \%$ \\
\hline & No & $30 \%$ & $35 \%$ & $27 \%$ & $31 \%$ & $29 \%$ & $38 \%$ & $28 \%$ & $33 \%$ & $27 \%$ \\
\hline \multirow[t]{2}{*}{ Allow to Play? } & Yes & $18 \%$ & $21 \%$ & $16 \%$ & $24 \%$ & $14 \%$ & $28 \%$ & $22 \%$ & $17 \%$ & $12 \%$ \\
\hline & No & $78 \%$ & $75 \%$ & $80 \%$ & $69 \%$ & $84 \%$ & $63 \%$ & $72 \%$ & $81 \%$ & $87 \%$ \\
\hline \multirow[t]{2}{*}{ Would Buy? } & Yes & $10 \%$ & $12 \%$ & $8 \%$ & $13 \%$ & $8 \%$ & $13 \%$ & $13 \%$ & $11 \%$ & $5 \%$ \\
\hline & No & $88 \%$ & $85 \%$ & $90 \%$ & $83 \%$ & $91 \%$ & $81 \%$ & $81 \%$ & $86 \%$ & $95 \%$ \\
\hline
\end{tabular}

Source : own elaboration.

However, it was found that Business Females showed significantly greater rejection of the doll than Art Males, with a Pearson Chi-Square of 0.021. No other combination showed significant differences: a Pearson Chi-Square of 0.492 for Art Females vs. Art Males, 0.065 for Art Females vs. Business Females, 0.440 for Art Females vs. Business Males, 0.178 for Art Males vs. Business Males, and 0.309 for Business Females vs. Business Males. Thus H2 can be said to be partially supported as Business (Females) showed significantly greater rejection than did Art (Males). At the same time, H3 is not supported - although partially 
reversed - in that Females (from Business), contrary to expectations, rejected the doll significantly more than Males (from Art).

$\mathrm{H} 4$ asserted that no ethnic group would show a significantly greater rejection of the Bebe Gloton doll than would other ethnic groups. The total combined response not allowing children to play with the doll was 78 percent, with 59 percent stating the product was immoral. Responses by four ethnic groups and a fifth category of non-American ranged from a high of 86 percent, for not allowing to play, to a low of 57 percent: 86 percent for Hispanics, 76 percent for European-Americans, 75 percent for African-Americans, 71 percent for Asian-Americans, and 57 percent for non-Americans. Determination of immorality ranged from a high of 66 percent to a low of 48 percent: 66 percent for Hispanics, 64 percent for African-Americans, 54 percent for European-Americans, 50 percent for Asian-Americans (although this statistic cannot be considered representative due to the small number of Asian-American respondents), and 48 percent for non-Americans. It was found that the variable Culture did significantly differ with regard to the variable Play, with a Pearson Chi-Square of 0.019. Contrary to expectations, there is a clear ethnic cultural disparity in the results (see Table 5 below) thus H4 is not supported.

TABLE 5. Tabulated results by ethnicity

\begin{tabular}{|l|c|c|c|c|c|c|c|}
\cline { 3 - 8 } \multicolumn{2}{l|}{} & Total & Euro - Am & $\begin{array}{c}\text { African } \\
- \text { Am }\end{array}$ & $\begin{array}{c}\text { Hispanic } \\
- \text { Am }\end{array}$ & $\begin{array}{c}\text { Asian } \\
- \text { Am }\end{array}$ & Non - Am \\
\hline Combined Results & N & 242 & 72 & 44 & 83 & 14 & 21 \\
\hline \multirow{2}{*}{ Immoral? } & Yes & $59 \%$ & $54 \%$ & $64 \%$ & $66 \%$ & $50 \%$ & $48 \%$ \\
\cline { 2 - 8 } & No & $30 \%$ & $35 \%$ & $27 \%$ & $22 \%$ & $43 \%$ & $43 \%$ \\
\hline \multirow{2}{*}{ Allow to Play? } & Yes & $18 \%$ & $22 \%$ & $18 \%$ & $8 \%$ & $29 \%$ & $43 \%$ \\
\cline { 2 - 8 } & No & $78 \%$ & $76 \%$ & $75 \%$ & $86 \%$ & $71 \%$ & $57 \%$ \\
\hline \multirow{2}{*}{ Would Buy? } & Yes & $10 \%$ & $11 \%$ & $11 \%$ & $7 \%$ & $1 \%$ & $29 \%$ \\
\cline { 2 - 8 } & No & $88 \%$ & $88 \%$ & $84 \%$ & $93 \%$ & $86 \%$ & $67 \%$ \\
\hline
\end{tabular}

Source: own elaboration.

\section{Discussion}

Initial assumptions were that Art students were more socially progressive than Business students, females would have greater acceptance of a female-oriented product than males, and that California students would be more socially progressive than Arkansas students (which is usually identified as a socially conservative culture). It was assumed that breast-feeding is considered to be a progressive feminist cause, and that 
progressives would therefore show greater acceptance of this doll product than social conservatives would.

The survey results do not most of these assumptions. As can be seen in Table 1, there is overwhelming CSUDH non-acceptance of this breast-feeding doll for 5-year-olds. A similar non-acceptance was found in Arkansas, however, Arkansas disliked it much less. 83 percent of CSUDH respondents would not allow children to play with the doll compared to only 70 percent at UALR and this difference was found to be statistically significant. Likewise, 63 percent of California respondents considered the product to be immoral compared to only 53 percent of Arkansas respondents.

Major questions are now raised about whether this doll truly represents progressive or conservative values; if there might be a stronger core of progressives at UALR than at CSUDH; or if there is greater public awareness and acceptance of the breast-feeding movement in Arkansas than in California.

At both campuses, Art favored the doll more than Business, which supports the idea that a breast-feeding doll (and the associated breast-feeding movement) represents progressive values; however, Males accepted the doll more than Females in both Art and Business. Male Art students proved to be the most tolerant towards the doll and Female Business students the most intolerant (and the difference between them was statistically significant). Additional questions that arise include: whether "because" the doll touches strongly on Female issues that Females reject the doll more than Males. Are Art Males somewhat more "liberal" than Business students AND less "progressive" than Female Art students; and therefore more tolerant than Females? Social commentators often claim that "progressives", being further from the mainstream, are more intolerant than centrist "liberals".

A supporting aspect to this view is that a number of respondents thought the doll was immoral because it was "Sexist". These comments were only made by CSUDH Art Females, which serves to support the initial assumption of CSUDH Female Art progressivism.

Ethnic background showed results that did not support H4. CSUDH Hispanics disliked the doll much more than any other group followed by European-Americans and African-Americans. Non-Americans at both campuses favored the doll far more than any other group or category (36\% at CSUDH "would let play" and 18\% "would buy"; $55 \%$ at UALR "would let play" and 45\% "would buy"). It has been claimed that American society is fundamentally socially conservative with a strong puritan bent and these results give some preliminary support to that as well as to the idea that this product carries with it cultural values that trespasses on a strong American taboo. Note that the small number of Asian-American respondents is a limitation of this result. Further data should be collected among different American ethnicities and from outside of the US to bring this into greater focus.

In terms of marketing, these numbers could represent a strong, although small, US niche market if those accepting the product have as much passion about it as the non-acceptors. 
Overall, a solid 10 percent indicated they would buy the doll if they had a daughter, with 15 percent indicating this at UALR and 7 percent at CSUDH. Although 29 percent of the non-Americans would buy, indicating that perhaps the US has a socially conservative culture, an overall 10 percent potential market share could be a solid basis for importing this product, especially if a target market can be identified keeping in mind that these results indicate Hispanic-Americans would purchase the doll at far lower percentages than other groups. The disparities between genders, college majors, and ethnicities give support that no one national US culture exists and that imports which seem to be rejected might have success if the market is segmented to find an accepting subculture [Thelen, 2003].

The survey's data and comments also offer some prescriptive implications in that it clearly identifies an American "moral" issue having to do with sexualization of children. While this issue may not be objectively logical from the standpoint of some other cultures, such as that of the product's Spanish origin, it obviously fits with US cultural attitudes. One possible marketing response, based on the literature and this survey's data, could be to change the design of the halter-top that accompanies the doll to make it more modest. Perhaps it can be eliminated entirely if another means can be found to activate the doll's electronic functions. In addition, the literature suggests that marketing products with sexual overtones can best be done with both an educational approach as well as the use of humor to defuse any negative cultural connotations [Cheng, 2009].

\section{Implications for Research}

This study finds that even when a foreign product import faces an overwhelming negative cultural response, some acceptance can be found in cultural subgroups. This acceptance may be as passionate as the disapproval when that disapproval is based mostly on cultural attitudes. This is so because cultural attitudes vary widely between subcultures and even within the same nation. The implication is that products which are culture-laden need to be matched with the appropriate subculture.

Further research is necessary to identify exactly what cultural attributes makes a difference between the genders, college majors, and ethnicities surveyed here. The small number of non-American respondents had a very different reaction than all of the US groups. Larger numbers of American ethnic respondents should be sampled. Similar groups should be surveyed in Spain, where this product originates, as well as in other countries. In addition, culture items that measure values and beliefs should be attached to the survey to more precisely determine what might be the causal factors in the acceptance and non-acceptance of this imported product. 


\section{Notes}

1 Authors e-mail address: wbrice@csudh.edu (corresponding author)

2 Authors e-mail address: echu@csudh.edu

3 Authors e-mail address: wjinternational@hotmail.com

\section{References}

Beard, F.K. (2008), How products and advertising offend consumers, Journal of Advertising Research, 48(1), pp. 13-21.

Bolton, S., Ledbetter, C. (1983), Compulsory bible reading in Arkansas and the culture of southern fundamentalism, Social Science Quarterly, 64 (September), pp. 670-676.

CBS News (2012, November 9). Breast-feeding baby doll raises eyebrows, support. CBS News. Retrieved from http://www.cbsnews.com/news/breast-feeding-baby-doll-raises-eyebrows-support/

Cheng, J. (2009, Oct 21), P\&G tackles Asian taboo, Wall Street Journal, retrieved from http://search.proquest. com/docview/399133785? accountid=10347

Chicago Tribune (2011, August 1), Let's play breast-feeding, Chicago Tribune, retrieved from http://articles. chicagotribune.com/2011-08-01/opinion/ct-edit-breastfeed-20110801_1_breast -feeding-lactation-bebe-gloton Cline, T.W., Kellaris, J.J. (2007), The Influence of Humor Strength and Humor Message Relatedness on Ad Memorability, Journal of Advertising, Vol. 36 (Spring), pp. 55-67.

Craig, C.S., Douglas, S.P., Bennett, A. (2009), Contextual and cultural factors underlying Americanization, International Marketing Review, 26(1), pp. 90-109.

de Mooij, M., Hofstede, G., (2002). Convergence and divergence in consumer behavior: Implications for international retailing, Journal of Retailing, 78(1), pp. 61-69.

Douglas, E.B., Lambert, R.D. (1990), Socialization into dominant vs. counter ideology among university-educated Canadians, Canadian Review of Sociology and Anthropology, 27 (November), 487-504.

Emmenegger, P., Manow, P. (2014), Religion and the gender vote gap: Women's changed political preferences from the 1970 s to 2010, Politics and Society, 42(2), pp. 166-193.

Fahy, J., Smart, D., Pride, W., Ferrell, O.C. (1995), Advertising Sensitive Products, International Journal of Advertising, 14(3), pp. 231-243.

Hofstede, G. (1980), Culture's Consequences: International Differences in Work Related Values, Sage, Beverly Hills, CA.

Hofstede, G. (2001), Culture's Consequences: Comparing Values, Behaviors, Institutions and Organizations Across Cultures, Sage, Thousand Oaks, CA.

Johanson, J., Vahlne, J.E. (1977), The internationalization process of the firm: a model of knowledge development and increasing foreign market commitments, Journal of International Business Studies, 8(1), pp. 23-32.

Krishnan, B.C. (2006), Towards intellectual globalization: a theoretical exploration and its implications for research, Journal of International Management, 12(2), pp. 196-207.

Madden, T.J., Weinberger, M.G. (1982), The Effects of Humor on Attention in Magazine Advertising, Journal of Advertising, 11(3), pp. 8-14.

McCracken, G. (1986), Culture and consumption: a theoretical account of the structure and movement of the cultural meaning of consumer goods, Journal of Consumer Research, 17(1), pp. 398-411. 
Parry, S., Jones, R., Stern, P., Robinson, M. (2013), Shockvertising: An exploratory investigation into attitudinal variations and emotional reactions to shock advertising, Journal of Consumer Behaviour, 12, pp. 112-121.

Peaceful Parenting, (2009, December 17), Bye-bye baby: Bebe Gloton sold out worldwide, Peaceful Parenting. Retrieved from http://www.drmomma.org/2009/12/bye-bye-baby-bebe-gloton-sold-out.html

Pope, N.K., Voges, K.E., Brown, M.R. (2004). The Effect of Provocation in the Form of Mild Erotica on Attitude to the Ad and Corporate Image, Journal of Advertising, 33(6), pp. 69-82.

Roof, W.C. (2007), Pluralism as a culture: Religion and civility in southern California, Annals of the American Academy of Political and Social Science, 612 (July), 82-99.

Sabri, O. (2012a), Preliminary investigation of the communication effects of "taboo" themes in advertising, European Journal of Marketing, 46(1), pp. 215-236.

Sabri, O. (2012b), Taboo advertising: Can humor help to attract attention and enhance recall? Journal of Marketing Theory and Practice, 20(4), 407-422.

Sojka, J.Z., Tansuhaj, P.S. (1995), Cross-cultural consumer research: a 20-year review, in: F. Kardes and M. Sujan, (eds.), Advances in Consumer Research, Association for Consumer Research, Provo, UT, pp. 461-474.

Sweeney, T. (1993), Becoming import status conscious, The Journal of European Business, 4(3), pp. 8-10.

Tews, I.C., Halliburton, C. (2014), Cross-cultural differences in response to product placements: A comparative study of the UK, Germany and Mexico, International Marketing Trends 2014 Conference Proceedings. Retrieved from http://www.marketing-trends-congress.com/ archives/2014/pages/PDF/326.pdf

Thelen, S., Ford, J.B., Honeycutt, E.D. (2003), Antecedents and consequences of consumer ethnocentrism across Russia’s three sub-cultures, American Marketing Association Conference Proceedings, 14, pp. 82-83.

Waller, D. (1999), Attitudes Towards Offensive Advertising: An Australian Study, Journal of Consumer Marketing, 16(3), pp. 288-294.

Van de Werfhorst, H.G., Kraaykamp, G. (2001), Four field-related educational resources and their impact on labor, consumption, and sociopolitical orientation, Sociology of Education, 74(4), pp. 296-317. 


\section{Appendix}

\section{Bebe Gloton Doll Survey}

The purpose of this survey is to determine market reaction to a new doll imported from Spain. This survey is completely anonymous.

A Spanish toymaker has developed a breast-feeding doll that comes with a special halter top its young "mothers" wear as they pretend to breast-feed their "babies." The halter top has daisies containing electronic sensors that cover the little girls' breasts.

The doll, called Bebe Gloton which translates as "gluttonous baby", makes sucking noises when its mouth is in proximity to the halter top sensors as it "feeds." Like many other dolls, Bebe Gloton can cry, signaling she wants more milk and can be burped in the same way a real baby would be.

Please turn the page to answer the survey questions.

1. What is your academic major?
2. (circle one) Are you:
(a) male or
(b) female

3. (circle one answer) How old are you?

- Under 18

- $18-24$

- 25-29

- $30-34$
- 35-39

- 40-49

- 50-59

- 60 or over

4. What do you consider to be your primary culture (circle BEST answer and complete)?
A. Not from America (please name country of origin
B. African-American (what is your home state?
C. Asian-American (what is your home state?
D. European-American (what is your home state?
E. Hispanic-American (what is your home state?
F. Native-American (what is your home state?
G. other American (what culture and home state?

5. (circle one) Is there anything immoral about this doll if it is for a 5 year old girl?

Yes No Not Sure

If Yes, the moral issue is most related to (circle one):
A. promotes early sexuality
B. could involve the uncovering of breasts
C. breast-feeding is not something to be encouraged
D. other (please state) 
6. (circle one) If you had a 5 year old daughter, would you let her play with this doll? Yes No Not Sure

7. (circle one) If you had a 5 year old daughter, would you buy this doll for her? Yes No Not Sure 